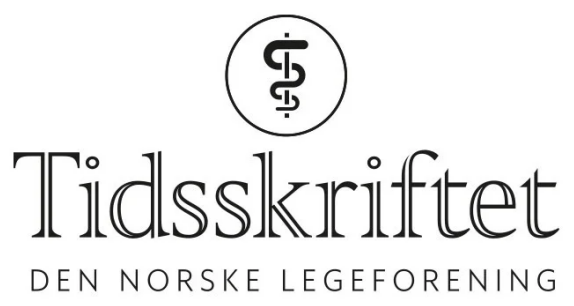

\title{
Akademia, fluefiske og hjertesvikt
}

INTERVJU

MARIT TVEITO

marit.tveito@me.com

Med en lakseelv som nærmeste nabo holder en av Norges mest siterte kardiologer til i Årdal i Ryfylke. Digitale flater gjør at han kan delta i internasjonalt hjertesviktarbeid før lunsj og i neste øyeblikk være på vei til elven eller innover fjellet. 


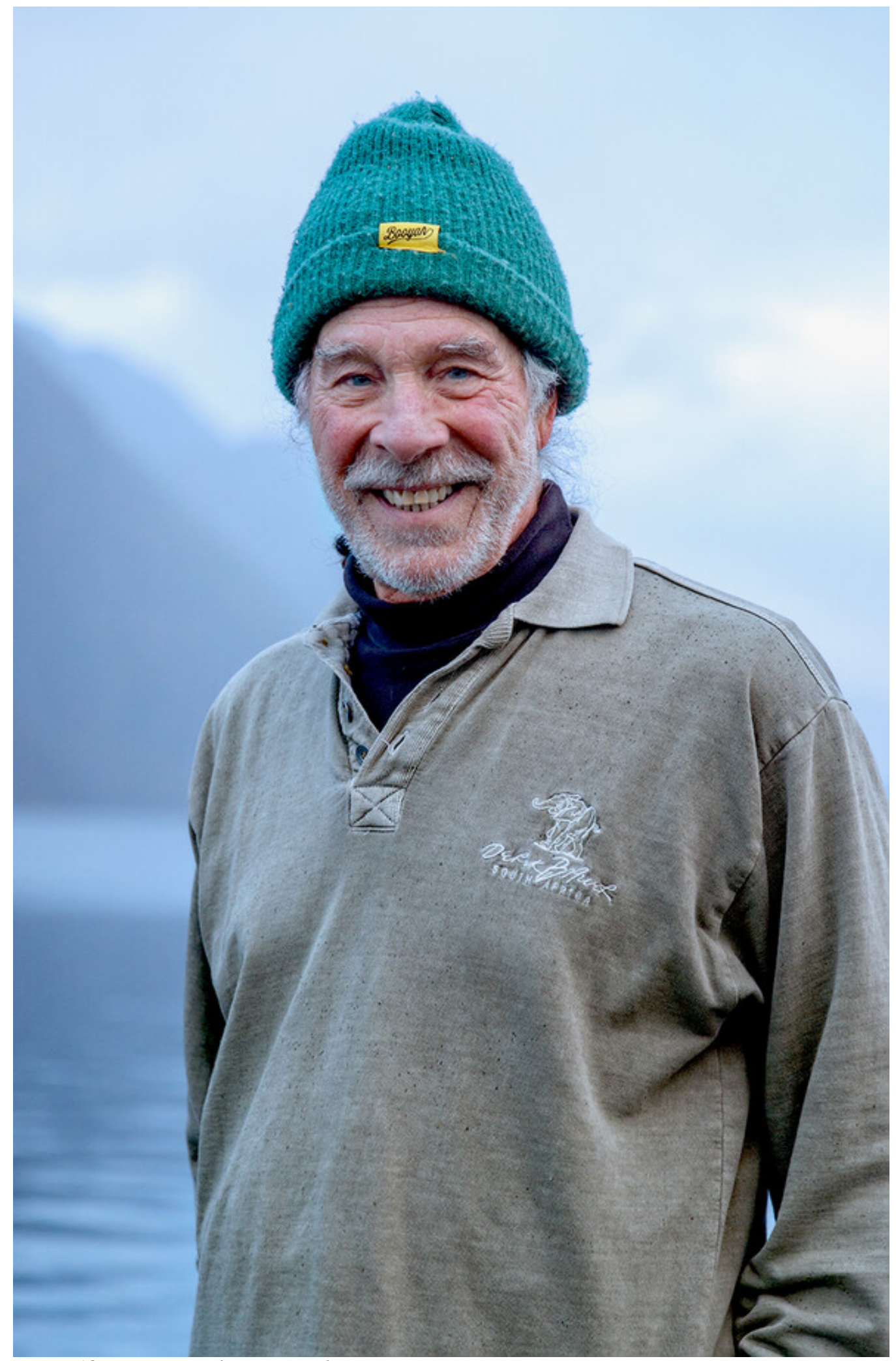

Foto: Alf Ove Hansen / Argus Media

- Vi kan vel ta dette intervjuet digitalt? Ingen trenger vel strengt tatt å møtes «face-to-face» lenger, nærmest insisterer Kenneth Dickstein.

- Dessuten sa jeg til kona at jeg ikke skulle klippe håret før pandemien var over, og det er den ikke.

Etter noen innledende innsigelser inviterer han hjem til et hus midt i naturen, omkranset av bratte fjell og et steinkast fra lakseelven og et utmerket ørretvann. Hunden ønsker velkommen først, og det er satt frem hjemmelaget kake og vegansk snacks. I forkant har jeg fått i hjemmelekse å sette meg inn i en nettside om hjertesvikt som Dickstein har ansvaret for, tilgjengelig på ti språk. I tillegg har Dickstein samlet en god del bilder og 
presentasjoner som ligger klart på Macen på stuebordet. Det er bilder av familien på alle vegger, men minst like mange bilder av fisk og fiskestenger. Her bor altså hjerteforskeren som i både 2014, 2015 og 2016 sto på lista over de én prosent mest innflytelsesrike forskerne i verden, med 460 publikasjoner på PubMed.

\section{En anglofil amerikaner}

Det er langt fra et Ivy League-universitet i Pennsylvania, hvor han var i samme årskull som den forhenværende presidenten Donald Trump, til Stavanger universitetssjukehus. Men så gikk jo reisen heller ikke rett dit.

\section{Kenneth Dickstein}

Født 9. april 1947

BA University of Pennsylvania

Cand.med. Royal College of Surgeons og University of London 1976

Spesialist i indremedisin 1985

Spesialist i kardiologi 1989

Ph.d. Universitetet i Bergen 1992

Professor ved Universitetet i Bergen 1999

460 internasjonale publikasjoner

President i Heart Failure Association of the European Society of Cardiology 2008-10

Nasjonalforeningens forskningspris 2016

Grunnlegger av og koordinator for heartfailurematters.org

- Hvorfor ble du lege? Og hvorfor i Norge?

- Faren min var en suksessfull pediater som hadde jobbet som lege i det amerikanske flyvåpenet under andre verdenskrig og deltatt på D-dagen. Da jeg var tolv år, tok han med hele familien til Europa for å vise oss kontinentet. Jeg ble hektet på Europa umiddelbart, og ferierte der hver sommer etter denne reisen. Broren min begynte å studere juss ved Cambridge, og tipset meg om at det var fint å studere medisin i Dublin ved Royal College of Surgeons. Europa virket mer lovende enn hjemlandet mitt på den tiden. I USA var Robert Kennedy og Martin Luther King blitt drept. Mange var desillusjonerte etter Vietnamkrigen. Jeg så for meg å etablere meg i London, og tok en dobbel medisinutdanning, hvor jeg gikk parallelt ved Royal College of Surgeons i Irland og University of London. Eksamenene falt på ulike tidspunkt, så jeg fikk god mulighet til repetisjon, og jeg fikk gullmedaljen i medisin for beste eksamen da vi var ferdige.

Han ble ikke værende lenge, for under studiet fikk han norske venner.

- De introduserte meg blant annet for Kvikk Lunsj, en sjokolade jeg har spist én om dagen av i førti år.

Hunden, Freia, er en sjokoladefarget labrador retriever og er oppkalt etter den norske sjokoladefabrikken.

- Mine norske venner tok meg med på ferie i Norge i påsken. Da syntes jeg at jeg hadde kommet til «the most beautiful place in the world».

Norge var og er et sosialistisk land, og det ga ham god samvittighet. 
- Nordmenn har sterke meninger, men er også beskjedne. Vi var i Holmenkollen og fikk se at en skihopper vant verdenscupen på hjemmebane. Da han ble spurt hvordan det føltes, var det første ordet han brukte i setningen, «nei ...». Det viser karakteristisk beskjedenhet, understreker han.

- Alle nordmenn begynner setningene med «nei».

\section{Hjertesvikt}

- Da jeg var ferdig på medisinstudiet, ga faren min meg abonnement på tolv medisinske tidsskrifter i en periode på ti år, en utrolig nyttig gave. Han sa: «Knowing the literature in your field is the key to success.» Og i New England Journal of Medicine leste jeg i 1980 om ACE-hemmeren kaptopril og hjertesvikt for første gang. På den tiden behandlet jeg en ganske ung mann med svært alvorlig hjertesvikt, og vi pøste på med vanndrivende uten særlig effekt. Hjertet så ut som en ballong, og mannen som en elefant. Etter å ha lest artikkelen, tok jeg kontakt med legemiddelfirmaet i USA, spurte om å få prøve legemidlet og forklarte at jeg hadde en egnet pasient. De spurte bare hvor mange tabletter jeg ønsket, og sendte meg hundre stykker i posten. Jeg vet ikke om jeg sa det til noen på avdelingen engang, nærmest humrer han.

«Etter et par uker gikk pasienten fornøyd ut av avdelingen og sa til meg:

'Doktor, det var en javlig sterk pille du ga meg'»

- Jeg ga ham 25 mg kaptopril etter frokost. Resultatet ble 16 liter diurese i løpet av to døgn, noe som gjorde det nødvendig med intens overvåkning og korrigering. Etter et par uker gikk pasienten fornøyd ut av avdelingen og sa til meg: «Doktor, det var en jævlig sterk pille du ga meg.» Han kunne sette seg på mopeden igjen og kjøre hjem i bedre form enn han hadde vært på lenge. Den opplevelsen var avgjørende for hva jeg skulle bruke arbeidstiden min på de neste tiårene. 


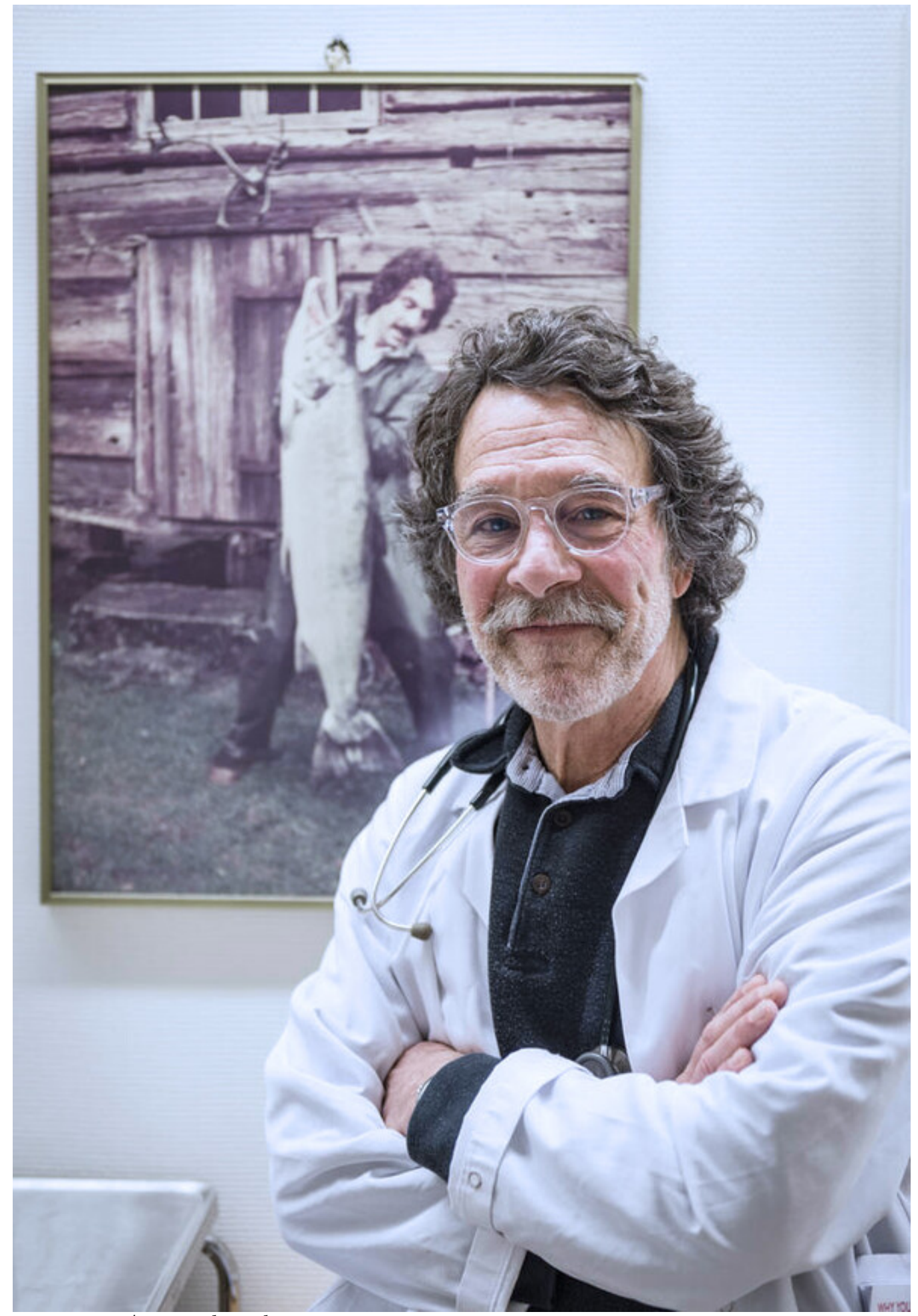

Foto: Privat / Kenneth Dickstein

Dickstein begynte å forstå den sentrale rollen endokrine systemer spilte i behandlingen av hjertesvikt, og skrev til Tidsskriftet for å informere sine norske kolleger. Artikkelen "Captopril ved hjertesvikt» kom på trykk i 1981. Avdelingen der han jobbet, la til rette for forskning på hjertesvikt, og han gjennomførte mange hemodynamiske og farmakologiske studier om ACE-hemmere og angiotensin II-reseptorblokkere. Han samarbeidet i mange år med Torbjørn Aarsland, en allsidig forskningssykepleier. Dickstein ledet etter hvert store internasjonale multisenterstudier om hjertesvikt. Innsatsen ble lagt merke til, og han ble invitert til å være forsker ved Brigham and Women's Hospital og Harvard Medical School.

- Det var en fristelse det var umulig å motstå. Jeg visste at foreldrene mine ville bli fra seg av glede. Kona var gravid, og vi flyttet sammen til Boston.

- Så kom dere tilbake igjen? 
- Ja, det var ikke slik jeg hadde sett det for meg. Det var en akademisk drøm, men arbeidskulturen var hektisk, og det var kamp om pasientene i klinisk forskning. Helsesystemet var privat og urettferdig. Jeg hadde pasienter som ikke hadde råd til en nødvendig invasiv intervensjon som PCI. Jeg lærte mye i Boston, men lengtet til Norge. Så ringte sjefen fra Stavanger og sa at de håpet vi kom tilbake. Vi tok avgjørelsen umiddelbart. Norge er et nydelig eventyrland med et godt rykte innenfor kardiologi.

\section{Internasjonal forskning}

Internasjonalt har han vært og er stadig engasjert i forskning.

- Jeg ble aktiv i European Society of Cardiology (ESC) tidlig, hvor arbeidsspråket er engelsk. Det er lettere å påvirke beslutninger når man bruker morsmålet sitt, konstaterer han.

- Lettere å være morsom også, legger han til. Han ble president i Heart Failure Association of the ESC og ledet arbeidet med «The ESC Guidelines for Heart Failure», felles retningslinjer for 51 land.

Han understreker at professor I-stillingen han fikk ved Universitetet i Bergen i 1999, var et «turning point» i karrieren.

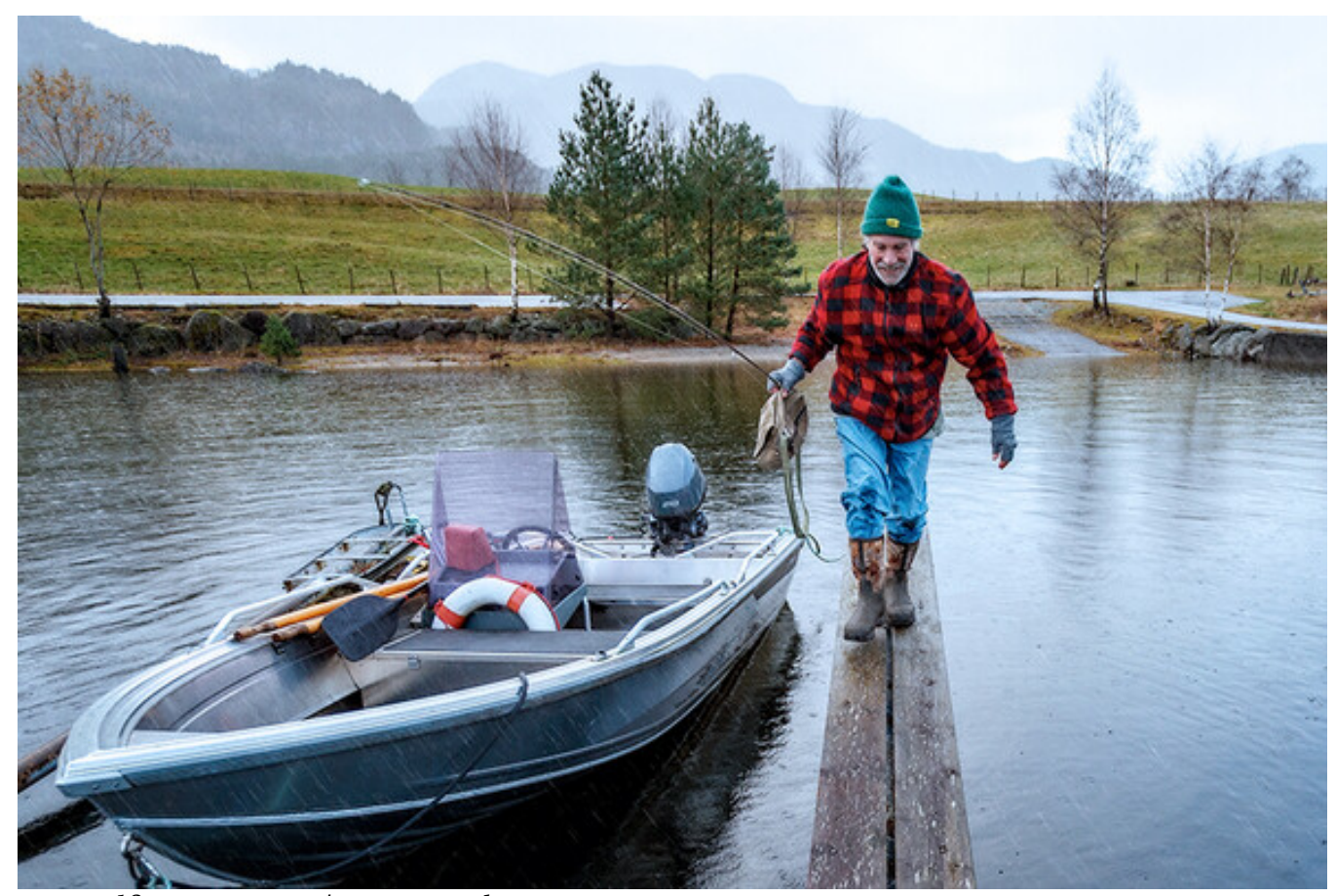

Foto: Alf Ove Hansen / Argus Media

- Samarbeidet med Universitetet i Bergen var meget bra. Akademisk kredibilitet er essensielt i akademisk forskning, og undervisning av studenter er "the spice of life». Doktorgraden min handlet for øvrig om effekten av medikamentell behandling på oksygenopptak hos pasienter etter hjerteinfarkt.

\section{Fiskeprat}

Dickstein har alltid vært lokalt engasjert og tydelig til stede på arbeidsplassen ved Stavanger universitetssjukehus.

- I 35 år stod jeg opp halv seks om morgenen for å være på jobben klokken syv. Jeg deltok på sykepleierrapporten på intensivavdelingen i 20 år sammen med studentene, før morgenmøtet.

På avdelingen henger også et stort bilde av ham og den største laksen han har fanget. 
- Fisk er en «icebreaker». Jeg har snakket med pasienter om fisken daglig i mange år etter at bildet ble hengt opp. Alle vil høre historien. Nordmenn forstår viktigheten av laks.

Familien bosatte seg kort vei fra sykehuset, og Dickstein foretrakk alltid moped fremfor bil, året rundt.

- Det er mer stimulerende med en mopedtur enn en kaffe om morgenen.

Dickstein er kjent for å stille høye krav til både seg selv, kolleger og studenter.

- Jeg vil at de som jeg veileder, har lest det siste innen forskning i feltet. Stipendiatene skal flytte grenser, og da må de vite hvor grensen går i dag. Jeg prøver å kombinere høye forventninger med humor, men alltid for å få alle til å strekke seg.

- Du brukte mye tid på medisinstudentene?

- Hele dagen. På slutten av dagen pleide jeg dessuten å sette av tid til en prat med en av studentene om hva som helst. Studenten styrte samtalen. De ettermiddagssamtalene «made my day».

Dickstein veksler nesten umerkelig mellom engelsk og norsk, gjerne midt i en setning.

- Jeg snakker stavangersk til pasienter, med amerikansk aksent. Dialekt kan brukes som krydder i språket.

\section{Portalen}

Før møtet har Dickstein gitt en hjemmelekse, nemlig å sette seg inn i ESC-nettsiden heartfailurematters.org.

- På et større hjertesviktmøte i Frankfurt med kardiologer, sykepleiere og representanter fra industrien stilte vi oss noen viktige spørsmål om hvorfor vi ikke klarer å kommunisere godt nok om hjertesvikt til pasienter, pårørende og helsepersonell. Vi ønsket å fremme bedre forståelse for tilstanden og å utdanne pasientene våre. 


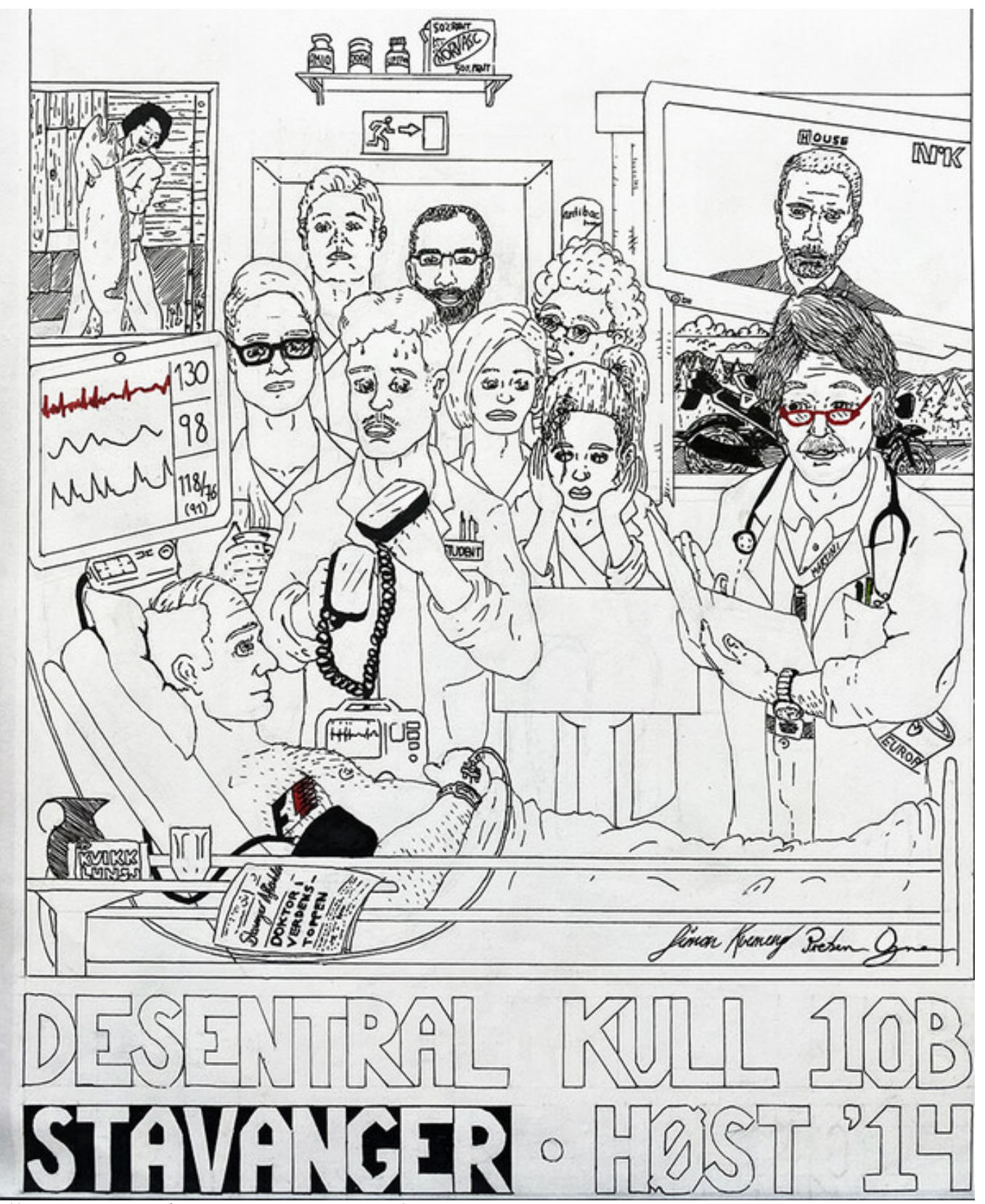

Illustrasjon: Preben Ogne og Simon Ulvenes Kverneng

- Hvordan skulle dere få det til?

- Det sier seg vel selv. På internett, selvfølgelig. Vi startet med en ESC-nettside på engelsk, men vi har nå oversatt den til ti språk. Nettsiden er nokså omfattende, men den er brukervennlig og full av attraktive seksjoner. Vi prøver å forbedre og oppdatere siden kontinuerlig, og det er det jeg bruker mest tid på nå. Det er faktisk det som aller mest gjør at jeg sover godt om natten, det å vite at jeg har bidratt til at så mange pasienter globalt har lest og lært om hjertesvikt den dagen.

\section{Den store fisken}

Rett etter krigen ble Eisenhower og Churchill invitert på laksefiske. Til samme strekning langs Suldalslågen ble Dickstein invitert, og besøksboka gikk tilbake til 1945 og nettopp Eisenhower og Churchill. Eisenhower fikk fire laks, Churchill ingen. I samme bok kunne Dickstein notere navn og fangst: en laks på $23 \mathrm{~kg}$.

- Den var så sterk at det var skremmende. Heldigvis var det en robåt tilgjengelig. Fisken dro oss av gårde som en hval, og slepte båten i nesten to timer. To personer måtte bruke en tomannshåv med halvannen meter i diameter for å få den opp. «A life-changing event», 
understreker han.

«Fisk er en 'icebreaker'»

Natur, sanking og fangst er nøkkelord i Dicksteins liv og hverdag. Da han møtte sin kone for 35 år siden, skjønte han at han måtte bli vegetarianer hvis han skulle ha noen mulighet, og det ble han raskt.

- Konen er egentlig den største fangst noensinne, smiler han.

- Og så har vi to voksne sønner som er meget ivrige fiskere og sørger for stor fangst.

Helt vegetarisk lever de ikke, fisk de har fanget selv er unntaket fra regelen.

- Og vi har fryseren full av laks og ørret, ler han.

- Vi lever godt her i Ryfylke. Jeg har traktor og elsker å bruke motorsag og hugge ved.

Vinteren er minst like bra som sommeren, vi går på ski flere ganger i uken og klarer nesten ikke å vente på mørketiden når sommeren er over.

Kontrasten er stor til hvordan søsteren og broren lever i USA. Det er lite han ville gjort annerledes i livet når han ser tilbake, men klimaforandringene er en stor bekymring også hos Dickstein.

- Dessverre har jeg en dyp uro over klimaet. Jeg frykter at livet på jorda vil styres etter jakten på vann. Broren min bor i California og lever omgitt av skogbranner. Permafrosten slipper taket, og Golfstrømmen skifter retning.

Helt $\varnothing$ kologiske er allikevel ikke alle interessene, og det viser seg at Europa-turene i ungdommen i stor grad handlet om å følge Grand Prix i motorsport fra land til land, en interesse han og broren fortsatt deler.

- Jeg tør nesten ikke si det, men jeg har en «little racing car» i garasjen. Han viser motvillig frem en rød Caterham, men lukker garasjeporten godt igjen før han setter kursen ut og oppover, for å ta igjen kona og hunden som har gått i forveien på fjellet.

- Jeg er heldig og svært fornøyd. Det er her jeg vil bo resten av livet.

Publisert: 7. januar 2022. Tidsskr Nor Legeforen. DOI: 10.4045/tidsskr.21.0802

(C) Tidsskrift for Den norske legeforening 2023. Lastet ned fra tidsskriftet.no 26. april 2023. 